\title{
Living the University Campus Spaces
}

\author{
Flavia Trebicka ${ }^{1}$ \\ ${ }^{1}$ Politecnico di Milano, PhD Candidate, ABC Department
}

\begin{abstract}
The university campus has been subject of many changes in recent years, this linked to social, cultural and economic changes. Technology evolution, globalisation and changes in educational programs are just some of the aspects that have contributed to these evolutions. Universities have always been avant-garde and experimental places that historically have reflected this aspect of their character in their physical spaces. Over the last 20 years, when there was an immediate acceleration of innovation and its interlocution in the way of living the campus, higher education spaces have not been able to translate their spatial needs in actions for the improving of learning infrastructure.

European reality has a millennial heritage of university campuses and a great extension of this heritage in the last century. This heritage, hosted in the main and secondary cities, was not able to give an innovative spatial response to the new ways of living the Higher Education and offer to the new users, the Millennials, a place suitable for their needs.

The research project, in order to define innovative intervention strategies for the improvement and innovation of Higher Education Spaces, aims to study the European university campus. The project primarily proposes the framing of the current state of campuses linked to the specific needs of different typology related to spaces that can be improved by strategic design and innovative facilities.

This research aims, through the study of best practices and research results, to define a pattern of indicators for the competitive renewal and regeneration of this category of spaces through strategic development and innovative methods to reach innovative and avant-garde uses that satisfy users. This means understanding the needs of European campuses in a global strategic context based on competition.

Ones that the research defines the tool of evaluation of the university spaces (focusing in campuses of technological fields) will be important to apply this pattern of indicators to a specific case study. This way the model that will be procured by the research can prove its efficiency in the field of investigation and crate new perspectives for the future of the university campus. The case study in question is the "Politecnico di Milano", an innovative and European excellence. This reality, like many other European universities, has plenty of spatial issues that could be improved.
\end{abstract}

Keywords: Higher Education, University Campus, New Perspectives, Strategic Development, Learning Infrastructure, Technological Evolution, Innovative Facilities, University Space

\section{Introduction}

In the last decades when technology, globalization, communication is changing our world, the places we live, must reflect these changes. Architects, designers, engineers that work in the fields of research or design have a moral obligation towards inhabitants to provide spaces, which follow the changes and respond to new necessities. Economic growth in emerging economies will continue to raise income levels over time, leading to an increase in the number of foreign students looking to study abroad. This will intensify the need for higher education institutions in more advanced economies [1] in prestigious Universities. In our days approaches to learning in educational settings are changing. Traditional teacher-centred models, where good teaching is conceptualized as the passing on of sound academic, practical, or vocational knowledge, are being replaced with student-centred approaches which emphasize the construction of knowledge through shared situations [2].

This research project wants to focus on the University Campus and to his future, considering the changes that come from the mutation and the development of the society. The University Campus host the new 
generations, the Millennials, born in the era of technology, grown with internet and used to have friends in different parts of the world, thanks to the easy ways of moving and sharing experiences and ideas.

The new generation needs to study and live in places that reflect their way of understanding the world. Nowadays most of the campuses aren't in line the expectations of their "inhabitants". According to a Gensler research, "today's campus spaces aren't working for students"[3]. Students don't find campus spaces effective. As this research (that has been made on more than 250 campuses) underline that student's satisfaction about spaces on their campus doesn't go beyond 36\%. In the situation, when campuses do not satisfy the needs of their users, this research project wants to give an answer to the need of new tendencies of spaces in the universities. It wants to respond to the questions how spaces of learning have to change in the variety of 21-century campuses through progressing strategic ideas and design concepts about the future of the university? The challenge is not to forget the existing building environment but to improve it through valorization and adaptation, with a view of generating an elite thought, which can be shared and co-developed further.

The research is interested in studying this process of changing through monitoring tools, case studies, interviews, questionnaires, models and the parameters of university rankings linked to space, facility and logistic. The purpose is to create a pattern of indicators that define the current state of the university campus through the monitoring tools to enable this research to activate universities to respond in real time to new needs arising from the development in the best possible way and estimate what they will need in the future.

The university campus encloses a dual nature of his environment, the one that feeds knowledge, conducts teaching and supports unique learning with the place of avant-garde science, young people, and energy of living. The dual nature is also found living the contemporary between innovation and tradition. This system based on the nature of universities creates an extrovert, dynamic and solemn physical environment at the same time. The situation in which universities are today, the $21^{\text {st }}$ century is an extremely challenging environment for successfully managing, designing and supporting university campuses. A city in miniature, must continually respond to external political and fiscal pressures, whilst simultaneously adapting to changing pedagogy and technology [4] communication, information and science.

\section{Contemporary Tendencies and Opportunities}

Over the course of the twentieth century the role of the campus underwent a series of transitions. Especially in the last century, the higher education became gradually more inclusive leaving aside the elite membership of universities. During the 1960s and 70s university campuses became places of radicalism, irreverence, politics and protest as well as hubs of artistic and cultural activity [5], reflection this way the sociological and economic evolution with which the society of XX century was faced.

In the last few years there has been a growing interest for the sector of Higher Education. Several initiatives, including many from the European Union, have confirmed a lot of projects that show particular interest in new university tendencies and their future projections.

The modernization process in the field of Higher Education is the subject of various researches in various parts of the world including Europe; from ones that comes from individual universities, to larger interventions commissioned agencies or more structured research required from governments. There are also national initiatives that support the new trends in higher education such as the Vivi.Polimi project, that is a self-financed initiative of "Politecnico di Milano" for improving the viability of the university campus through physical and virtual actions in order to support new trends of spaces assist by facilities. It is worth noting that in the last period issues that concern Higher Education and spaces and facilities, used by these institutions, have changed. No longer we can think of a classical concept of teaching and classical places where study, work and life take place in universities.

Since the beginning of 2017 the Milan Polytechnic commissioned to a research group, in those I'm part of, to undertake a project for the rethinking of the campus spaces. 
This initiative focuses on the spaces addressed to students and academics of the Polytechnic of Milan, with an inclusive approach to the stakeholders and a vision of the dialogue campus-city, valorizing the existing spaces and creating new elements for a place suitable with a university of excellence. The project face the issue of the growing demand for quality space that implies having a place that meet the needs of users.

Jisc in "Designing Spaces for Effective Learning" [6] outlines a very simple set of principles that universe campus space should be:

-Flexible - to accommodate both current and evolving pedagogies;

-Future proofed - to enable space to be re-allocated and reconfigured;

-Bold - to look beyond tried and tested technologies and pedagogies;

-Creative - to energize and inspire learners and tutors;

-Supportive - to develop the potential of all learners;

-Enterprising - to make each space capable of supporting different purposes.

On one hand, the various reports and research results on the future of universities have highlighted the problems that these realities have today and what they have to face to follow-on impact; on the other hand these interventions are a hint to reflect on the fact that today, globally and in particular European countries, are looking for ways to adapt methods and projects in accordance with the innovative needs that new users (millennials) require. The academic mission continues to evolve, creating new types of campus growth needs. New technologies, discoveries, and societal issues require facilities that support innovation and collaboration in new ways and at new scales [7] with potential partners that can be found for shared use, shared management or shared own ship for the required campus functions [8].

Considered in their complexity, university campuses do not correspond to an disconnected relation but constitute an important community with great potential that influences urban and territorial dynamics independent of the ultimate goal is the evolutionary process of the university campus.

The question of the growing demand for innovation and physical quality, supported by services, and the evolution of the concept of the place of higher education, is so therefore an important aspect that has a high impact on its users and on the urban environment that hosts it.

The issue of growing demand for innovative and physical quality spaces supported by facilities, technology and the evolution of the concept of place of Higher Education, is therefore addressed.

\section{Project Description}

\subsection{General Objectives}

The general objective of the research is to provide a tool that consist in a pattern of indicators that will help for the design, modernization, valorization and the innovative use of university campus spaces, considering them as the infrastructure of excellence. This tool will support university in the proses of valuation of the existing spaces and will stimulate the improvement through the supply of potential resources that will induce innovation and new approaches to grant a new vision of these institutions.

For this purpose, after the considerations made within the European context, the themes that emerge and the ones that have been considered with value for research are:

- the creation of methodological processes which respond to the growing need for shared tools to support innovation in the spatial environment of the Higher Education through innovative spaces that are comparable - an innovative approach to spatial management of university campuses, which can allow mutations and changes that may occur in the life cycle of these structures that arise in urban contexts 
- the design of effective spaces for students and professors consisting in innovative design supported by services and technologies that makes the learning and research spaces appropriate for those who need to work/study/socialize in the spatial context of university campuses

The research project is therefore based on the idea of an integrated cooperation between different sectors and different actors to create value, optimize resources and create a strategic development model. This model should be adaptable to any university structure to support them in the present and project them into the future through the study of innovative design and management approaches.

Other objectives of the research that will help to arrive final goals mentioned above, will be:

- build a comprehensive overview of the trends of 21-century European University campuses

- define the physical and virtual actors that influence changes in the way universities are lived

- establish indicators for the livability and the sustainability that, together with monitoring and signaling, will allow a continuous improvement of the Higher Education space

- generate future space models for campuses in response to demand and supply

- estimate the typologies and the amount of space the university campus will need in the future

- generate planning and management processes that maximize the use of space

\subsection{Methodology}

\subsubsection{Definition of the Contextual and Cultural Scenario:}

The first phase of the research project is analytical and descriptive; it's performed through bibliographic surveys. This desk research carried out within this project to improve our understanding of the current situation. It aims to comprise the scenario where universities live today, which are the new trends in Higher Education and what changes are made in education programs.

Understanding how users needs have changed and what are the opportunities and limitations that technology and globalization offers are fundamental points of the research. At this stage, the project want to understand the evolution of university campuses and the radical changes they have had in recent decades under the pressure of new trends. After this step the intent is to move in an urban scale and understand how these structures of excellence that act as cities in cities become urban integrators. This phase is considered particularly important because it defines the scenario in which the research will take place.

\subsubsection{Identification of the Contemporary Tendencies:}

Having clear, from the firs part of the research project the scenario in which university campuses perform today, the intent is to continue and investigate trends and improvement strategies adopted by various niche universities within the European area. The research will focuses on the consultation of outcomes documents produced for government agencies by funded research and EU reports to understand in what direction and which actions are considered advisable in this field of interest.

The research will continue in this second step, which remains midway between the state of the art and "operational" part, with consulting best practices and investigate the uses of their spaces with the purpose of understanding, in this structure of excellence, how spatial problems are faced and how the services help these knowledge-producing machines. At this stage there is no distinction in the selection of campuses for universities typologies fields. The interest is to get the strategies that address the issues of space enhancement through innovation and flexible realities that stimulate users to live campus sites 24/7. 


\subsubsection{Critical Analysis and Placement of Research in the European Technical University Scenario:}

The analysis of best practices at European level, compared with the results of European research, highlights the need of acting in common areas through criteria that could distinguish in relation to the needs of teaching and research typologies, that today each university performs within it.

Starting from this presupposition, the research, in fact, aims to narrow the field of inquiry and try to understand how the universities of technical disciplines (polytechnic universities) develop within them the needs of spatiality. Mapping the spatial typologies that occupy each function and making a comparative analysis in terms of percentage can be an effective method for the research (in this way the research project will have the opportunity to compare campuses of different sizes with different amounts of users and have meaningful answers). It could be made also a space evaluation using tools such POE (post occupancy assessment).

At this phase it should also be necessary to understand witch are the strengths and the trends in place of the selected samples through semi-structured interviews with staff, analysis of documents of the technical and management offices, and the consulting of projects and initiatives for space and life improvement.

-Selection of the case study and definition of the pattern of indicator:

From the moment that spatial typologies of best practices of European technological universities will be mapped and the phase of bibliographic consultation will be completed, it will be possible to draw relevant indicators that set the criteria for the campus state. Through these indicators, the research will be able to create a template tool the supports the projection of university spaces in the future. This can be a supportive tool for all European universities that works in technology fields.

Then will be establish a case study in which this tool can be applied. Considering that this research takes place in one of the most important European university in the fields of technology, the Polytechnic of Milano, considering that currently this institution has many initiatives concerning the improvement of spaces, (which should be completed at the time of the instrument's investigation), has been regarded that would be appropriate for the reasons mentioned above that the case study become the "Polytechnic of Milan".

\section{References}

[1] Arup (2012), Future of campus, Foresight + Research + Innovation, Arup, London.

[2] P. G. Altbach, J. Knight, (2006), A report for the Scottish Funding, Council, Spaces for learning a review of learning spaces in further and higher education, The Internationalization of Higher AMA Alexi Marmot, Associates in association with haa design; available at http://aleximarmot.com/userfiles/file/Spaces\%20for\%20learning. Pdf accessed on may 2017

[3] Gensler (2012), Design + Performance Report, Changing Course. Connecting campus design to a new kind of student, available at https://www.gensler.com/uploads/documents/Changing_Course_Survey_10_08_2012.pdf accessed on March 2017.

[4] J. Coulson, P. Roberts, I. Taylor , University Trends: Contemporary Campus Design, , UK: Oxon, Routledge, 2015.

[5] D. J. Neurman, Building type basics for college and university facilities, USA: New Jersey, Wiley, 2013

[6] JISC (2012), Designing Spaces for Effective Learning, A guide to 21st century learning space design, available at https://www.jisc.ac.uk/elearning_innovation accessed on March 2017.

[7] Harvard University (2013), Harvard University's Campus in Allston available at http://home.planningoffice.harvard.edu/files/hppm/files/harvard_imp_2013_0.pdf accessed on April, 2017.

A. Heijer, Managing the university campus, Nl: Delft, Eburon Academic Publisher, 2011. 